\title{
Além da timeline: a contribuição dos infográficos para o ensino de História da Arte
}

\author{
Beyond the timeline: the contribution of infographics to the teaching of Art History
}

\author{
Marcele Cristiane Minozzo, Carolina Calomeno Machado
}

design da informação, infográficos, ensino de arte

\begin{abstract}
A História da Arte é indissociável da história da humanidade e envolve conceitos que nem sempre são de fácil entendimento aos estudantes de ensino médio. A não familiaridade com o conteúdo e a lentidão da narrativa verbal podem levar à falta de compreensão e desinteresse pelo tema. Os infográficos têm o potencial de tornar mais eficiente a visualização de dados complexos. O objetivo deste artigo é reflexionar se infográficos podem ser utilizados como recursos didáticos no sentido de aproximar o(a) aluno(a) de ensino médio dos conceitos presentes na história da arte com uma linguagem mais próxima de seu repertório. Para tanto fez-se um compêndio de abordagens e teorias de aprendizagem e suas áreas de convergência apontaram para a necessidade de relacionar o conteúdo com a realidade dos alunos. Como as redes sociais são cada vez mais acessadas por jovens em idade escolar, realizou-se a análise de três exemplos extraídos de uma plataforma de compartilhamento de imagens que mostrou que estes artefatos organizam as informações de forma clara e concisa com linguagem mais acessível, e podem ser utilizados em contexto escolar. Porém, é importante ressaltar a necessidade de acompanhamento docente quanto à confiabilidade das fontes dos dados extraídos da internet.
\end{abstract}

information design, infographics, art education

Art History is inseparable from the history of mankind and involves concepts that are not always easy for high school students to understand. Unfamiliarity with the content and the slowness of the verbal narrative can lead to a lack of understanding and lack of interest in the topic. Infographics have the potential to make complex data visualization more efficient. The purpose of this article is to reflect on whether infographics can be used as teaching tools to bring high school students closer to the concepts present in art history with a language closer to their repertoire. To this end, an overview of learning approaches and theories was made and their areas of convergence pointed to the need to relate the content to the students' reality. As social networks are increasingly accessed by young people of school age, an analysis was made of three examples extracted from an image sharing platform that showed that these artifacts organize information in a clear and concisely way with more accessible language, and can be used in a school context. However, it is important to emphasize the need for teacher monitoring as to the reliability of the sources of data extracted from the internet.

\section{Introdução}

A produção humana a que chamamos arte traz informações sobre a estrutura social e política, valores, hábitos e costumes de um povo, um determinado lugar ou um período. Se assim considerarmos, "nenhum povo existe no mundo sem arte" (Gombrich, 2015, p. 39). Compreender

Anais do $10^{\circ} \mathrm{CIDI}$ e $10^{\circ} \mathrm{CONGIC}$

Kelli C.A.S. Smythe, Rafael de Castro Andrade (orgs.)

Sociedade Brasileira de Design da Informação - SBDI

Curitiba | Brasil | 2021
Proceedings of the $10^{\text {th }} \mathrm{CIDI}$ and $10^{\text {th }}$ CONGIC

Kelli C.A.S. Smythe, Rafael de Castro Andrade (orgs.)

Sociedade Brasileira de Design da Informação - SBDI Curitiba | Brazil | 2021 
a História da Arte, portanto, pode ser complicado para estudantes do ensino médio. Mas como tornar mais acessível um conteúdo complexo? O Design da Informação e, em especial, os infográficos podem contribuir na visualização e compreensão de informações importantes?

Segundo Mello (2016) a lentidão da narrativa verbal, seja oral ou escrita, para comunicar conceitos essenciais pode levar à falta de compreensão e, consequentemente, ao desinteresse pelo conhecimento. A autora afirma ainda que dispositivos de síntese, como os infográficos, podem ser uma forma de apresentar algo novo e que, depois de compreendidos, tornarão mais acessível a especialização no tema.

Os materiais didáticos têm sido afetados pelas tecnologias contemporâneas, em especial a digital, enfatizando o uso de imagens. A utilização de representações visuais como forma de ilustrar ou mesmo complementar um conteúdo textual é importante e a leitura de imagens deve ser incentivada em sala de aula. Deve-se, no entanto, considerar o contexto e repertório visual dos estudantes, uma vez que a familiaridade do leitor com a informação gráfica é fundamental na compreensão da mensagem. (Coutinho, 2006).

"Artefatos visuais podem ser projetados com intuito de orientar, ensinar, informar e/ou explicar, de forma a potencializar o entendimento e assimilação da informação, tornando-a conhecimento para o público". (Oliveira et al., 2017 p.288). Para uma utilização mais extensiva e aprofundada das imagens no processo de ensino-aprendizagem é necessário estimular um olhar atento e a interpretação daquilo que se vê. (Coutinho, 2006).

Este artigo busca refletir acerca da contribuição dos infográficos como ferramentas no ensino de Arte para alunos(as) de ensino médio. Para tanto recorreu-se a algumas teorias cognitivas difundidas no Design da Informação e a abordagens de ensino das Artes Visuais, delineando aspectos de convergência entre as mesmas.

Também buscou-se conceituar e tipificar infográficos, e elencar alguns requisitos para a definição daqueles que poderiam ser considerados eficientes, para então analisar, a partir destas premissas, três exemplos que representassem estratégias de ensino em História da Arte: a leitura de uma obra de arte, a produção de um artista e as características de um estilo ou movimento artístico.

\section{Arte, Design e Infografia}

Arte e Design são áreas análogas. Se o Design nasce da Arte e nela baseia-se (Cardoso, 2008; Maass, 2011; Mozota, 2003), não deveria soar estranha a sugestão de se utilizar princípios de Design para a análise de obras e compreensão de conceitos em Arte. Mas é fato que o Design se consolidou como área do conhecimento e se afasta da subjetividade da Arte conforme se especializa. Conforme definição da Sociedade Brasileira de Design da Informação (SBDI, 2020), este é

uma área do Design cujo propósito é a definição, planejamento e configuração do conteúdo de uma mensagem e dos ambientes em que ela é apresentada, com a intenção de satisfazer as necessidades informacionais dos destinatários pretendidos e de promover eficiência comunicativa. 
A infografia, por sua vez, é dos artefatos produzidos pelo Design de Informação, justamente por preconizar o conteúdo informacional e a eficiência comunicacional. O termo infografia é um neologismo adotado entre as décadas de 1970 e 1980 quando do uso intenso no jornalismo, nos Estados Unidos como information graphics ou gráficos de informação, logo passando a ser infographics.

Segundo Rajamanickam (2005) infográficos são elementos visuais que auxiliam na compreensão de um determinado conteúdo baseado em texto.

Infográficos podem ser definidos ainda como artefatos gráficos que integram imagens, textos, símbolos e/ou esquemas com o objetivo de apresentar dados ou conceitos, que podem ser complexos, de forma clara e concisa. (Lonsdale \& Lonsdale, 2019; Mello, 2016; Naparin \& Saad, 2017; Oliveira et al. 2017, Siricharoen, 2013).

Já a principal função da infografia seria, segundo Ribas (2004), a de "facilitar a comunicação, ampliar o potencial de compreensão pelos leitores, permitir uma visão geral dos acontecimentos e detalhar informações menos familiares ao público".

Como parte do campo da visualização de informações, estes artefatos lideram na comunicação de notícias e podem ser vistos em diversas mídias, de negócios a redes sociais, e também podem ser usados como ferramenta de aprendizagem na educação (Naparin \& Saad, 2017).

Moraes (2013 apud Escobar \& Spinillo, 2016) faz uma classificação dos infográficos por sua natureza, a partir das questões a que buscam responder, em:

- exploratórios: o quê? quem? onde?

- explanatórios: como? ou por quê?

- historiográficos: quando?

Uma vez que os infográficos são artefatos gráficos é possível analisá-los pela matriz de Twyman (1979) que visa tipificar os modos de simbolização e métodos de configuração gráfica (figura 1) e será utilizada na análise dos objetos desta pesquisa.

Figura 1: Matriz de possibilidades de abordagem gráfica. Fonte: Adaptada de Twyman, 1979

\begin{tabular}{|c|c|c|c|c|c|c|c|c|}
\hline \multicolumn{9}{|c|}{ Método de Configuração } \\
\hline \multirow{5}{*}{ 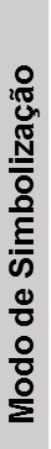 } & & Linear & $\begin{array}{l}\text { Linear } \\
\text { Interrompida }\end{array}$ & Lista & $\begin{array}{l}\text { Linear } \\
\text { Ramificada }\end{array}$ & Matriz & $\begin{array}{l}\text { Não Linear } \\
\text { com } \\
\text { visualização } \\
\text { direcionada }\end{array}$ & $\begin{array}{l}\text { Não linear } \\
\text { aberta }\end{array}$ \\
\hline & $\begin{array}{l}\text { Verbal/ } \\
\text { Numérica }\end{array}$ & 1 & 2 & 3 & 4 & 5 & 6 & 7 \\
\hline & $\begin{array}{l}\text { Pictórica e } \\
\text { Verbal/ } \\
\text { Numérica }\end{array}$ & 8 & 9 & 10 & 11 & 12 & 13 & 14 \\
\hline & Pictórica & 15 & 16 & 17 & 18 & 19 & 20 & 21 \\
\hline & Esquemática & 22 & 23 & 24 & 25 & 26 & 27 & 28 \\
\hline
\end{tabular}


Rajamanickam (2005) elenca algumas estratégias que podem ser utilizadas na elaboração de um infográfico eficiente, e que serão também observadas na análise dos objetos a seguir:

- Organizar as informações: definir o que é relevante

- Tornar visíveis: como devem ser apresentadas

- Estabelecer contexto: trazer informações complementares

- Simplificar: informações essenciais, uso de poucas cores e detalhes

- Adicionar redundância: Reforçar informações, mas sem exagerar para não entediar o leitor

- Mostrar causa e efeito

- Utilizar comparações e/ou contrastes

- Criar dimensões múltiplas (outras camadas de informação)

- Integrar dados, aproximar as informações, preferencialmente em uma mesma página, de forma que se crie uma "história coerente"

Outros recursos podem ser utilizados para promover a compreensão de conteúdos complexos ou abstratos, como figuras de linguagem e metáforas visuais, que alteram o significado original de algum elemento, ou representações conotativas, com linhas simplificadas e menos realistas. O emprego destes recursos também possibilita infográficos mais atrativos, aumentando o interesse dos leitores. (Escobar \& Spinillo, 2016).

Algumas operações retóricas, como as propostas por Durand (1970, apud Escobar e Spinillo, 2016) também podem auxiliar a compreensão de conceitos. A adição de novas camadas de informação para contextualizar ou explicar algo que não está explícito, a supressão de algum elemento para que seja possível "enxergar" além (por exemplo, a retirada de uma parede para visualizar o interior de uma construção), a substituição ou troca de algum elemento por outro que seja mais compreensível (por exemplo, utilizar um escudo no rosto, no lugar de uma máscara facial para representar a proteção contra doenças de contágio respiratório).

Os infográficos podem contar histórias de forma bastante simples, combinando-se uma boa visualização de dados, um design gráfico atrativo e um roteiro, com introdução, mensagemchave e conclusão. (Naparin \& Saad, 2017).

\section{Ensino da História da Arte no Ensino Básico}

\section{Conexão dos conteúdos curriculares com os saberes e o cotidiano}

Para que a aprendizagem aconteça de forma efetiva o professor deve buscar relacionar o que ensina com os acontecimentos do cotidiano, a realidade e os saberes dos estudantes.

(Barbosa, 2005; Brasil, 2018; Cook, 2006; Freire, 2002; Moreira, 2014).

De acordo com a Base Nacional Comum Curricular as estratégias didático-pedagógicas para o envolvimento dos estudantes passam por uma seleção e aplicação de metodologias diversificadas, recursos complementares e a contextualização dos conteúdos dos componentes 
curriculares, "identificando estratégias para apresentá-los, representá-los, exemplificá-los, conectá-los e torná-los significativos, com base na realidade do lugar e do tempo nos quais as aprendizagens estão situadas" (Brasil, 2018, p.16)

Na seleção de recursos visuais complementares, além das informações adicionais, é importante verificar se a forma de apresentação é eficaz e adequada ao público a que se destina. Realizou-se, portanto, um levantamento em teorias cognitivas abordadas em estudos da área do Design da Informação, substanciais na produção destes materiais, e abordagens difundidas no ensino-aprendizagem de Artes Visuais (tabela 1) e verificou-se dois aspectos de convergência: a) que a combinação da linguagem verbal com imagens pode facilitar a compreensão; e b) que os conhecimentos prévios sobre um tema são requisitos importantes para a aquisição de novos conhecimentos.

Tabela 1: Aspectos de convergência entre teorias e abordagens de aprendizagem. Fonte: as autoras

\begin{tabular}{lll}
\hline Teorias de Aprendizagem & $\begin{array}{l}\text { Conhecimentos prévios como } \\
\text { fator determinante }\end{array}$ & $\begin{array}{l}\text { Combinação de linguagem } \\
\text { pictórica e verbal }\end{array}$ \\
\hline $\begin{array}{l}\text { Abordagem Sociocultural de } \\
\text { Paulo Freire (Freire, 2002) }\end{array}$ & Repertório de vida, cotidiano & $\begin{array}{l}\text { Imagens cotidianas na } \\
\text { alfabetização }\end{array}$ \\
$\begin{array}{l}\text { Abordagem Triangular de Ana } \\
\text { Mae Barbosa (Barbosa, 2005) }\end{array}$ & Contextualização & Leitura de imagem \\
$\begin{array}{l}\text { Teoria da Aprendizagem } \\
\text { Significativa de David Ausubel } \\
\text { (Moreira, 2014) }\end{array}$ & $\begin{array}{l}\text { Conhecimento prévio determina a } \\
\text { aquisição de novos conceitos }\end{array}$ & Modelo Mental \\
$\begin{array}{l}\text { Teoria da Carga Cognitiva Sweller } \\
\text { (Cook, 2006) }\end{array}$ & $\begin{array}{l}\text { Acesso à memória de longo prazo } \\
\text { reduz carga }\end{array}$ & Representações Múltiplas \\
$\begin{array}{l}\text { Teoria Cognitiva de } \\
\text { Aprendizagem Multimídia de } \\
\text { Meyer (Rudolpf, 2017) }\end{array}$ & Memória de longo prazo & $\begin{array}{l}\text { Memória sensorial } \\
\text { Modelo verbal/pictórico }\end{array}$ \\
$\begin{array}{l}\text { Teoria da Dupla Codificação de } \\
\text { Paivio (Frederico \& Gianotto, }\end{array}$ & $\begin{array}{l}\text { Interação da Memória com novos } \\
\text { co18) }\end{array}$ & Imagen e Logogen \\
\hline
\end{tabular}

A Teoria da Dupla Codificação de Paivio (Frederico \& Gianotto, 2018) descreve a cognição como processo que deriva de estímulos verbais e não verbais, que são processados em sistemas independentes mas que interagem entre si, e a memória como fator inerente ao conhecimento.

Segundo a teoria de David Ausubel (Moreira, 2012) a aprendizagem significativa é um processo cognitivo em que os conhecimentos prévios são associados ao novo conteúdo para que novos aprendizados sejam construídos. O "fator mais importante é o que já se sabe" então os materiais utilizados devem ter uma linguagem familiar ao aluno (Moreira, 2012).

A Teoria da Carga Cognitiva de Sweller (Cook, 2006) assinala que representações múltiplas (verbal e visual) podem reduzir carga na memória de trabalho e que a integração dos conhecimentos prévios reduz esforço cognitivo, influenciando na atenção, interpretação e aprendizagem de novos conceitos. Os alunos que não possuem familiaridade com o tema podem ter dificuldade em distinguir o que é relevante. Neste sentido, a eficácia na transmissão 
da mensagem depende de dados organizados e apresentados de forma que possuam um valor informacional de acordo com o perfil dos usuários (Oliveira et. Al. 2017).

Deve-se buscar, portanto, uma linguagem que seja eficiente para o entendimento do público a que se pretende atingir, neste caso os estudantes de ensino médio. A internet e as redes sociais fazem parte do cotidiano destes estudantes. Segundo uma pesquisa da Global Web Index, que analisou dados dos maiores mercados de internet do mundo, o Brasil é o segundo país em que se passa mais tempo médio por dia em sites ou aplicativos de mídia social e 225 minutos é o tempo médio diário que o brasileiro permaneceu conectado em 2019. A faixa etária mais presente entre os usuários é a de 16 a 24 anos, ou seja, jovens em formação. Os smartphones e as redes sociais são utilizados para diversas atividades, inclusive como fonte de informação. (Duarte, 2019).

Há uma grande quantidade de material multimídia à disposição dos professores, que podem utilizá-los para proporcionar experiências de aprendizagem de qualidade para os alunos. Os desafios, neste caso, são: realizar melhor seleção dos recursos (Yu; Brandenburg, 2011) e verificar se o artefato foi elaborado consideradando-se a ética, utilização de dados reais, sem estimativas ou distorções (Siricharoen, 2013).

Os materiais produzidos para serem compartilhados em redes sociais são, geralmente, mais facilmente compreensíveis para um público "não especialista". Portanto, utilizar imagens de meios noticiosos, associadas a uma linguagem coloquial e despretensiosa pode ajudar a vencer a barreira imposta pelo vocabulário rebuscado e a erudição dos livros de arte e reduzir o afastamento sentido pelos estudantes, sobretudo àqueles que não tiveram em sua trajetória um contato com a arte acadêmica, em museus.

\section{Infográficos no Ensino da História da Arte}

As timelines, ou linhas do tempo, são infográficos historiográficos bastante difundidos no campo da Arte, seja em exposições em museus, catálogos, materiais de divulgação, sites, como em livros, pedagógicos ou não, que tratem da História da Arte. Livros "técnicos" e biografias de artistas, não raro, apresentam dados historiográficos em timelines.

Em uma linha do tempo, recursos metafóricos como espaços temporais podem ser comprimidos, acelerados, expandidos, para adequação ao espaço visual dependendo do objetivo da apresentação (Cánovas et. al., 2011).

Na timeline (figura 2) extraída de um livro didático ${ }^{1}$ da disciplina Arte do primeiro ano do ensino médio, observa-se o uso de imagens para ilustrar cada um dos períodos descritos nos espaços temporais e, textualmente, são inseridas as datas e características, acontecimentos, invenções ou descobertas que marcam cada período. Neste caso há uma deformação nos espaços temporais para adequação da representação visual em uma única linha. Os períodos da Pré-História, que se referem à milhões e milhares de anos ocupam um espaço na representação visual similar aos da Antiguidade, Idade Média e Moderna cuja relação temporal

\footnotetext{
${ }^{1}$ Capítulo de Artes em: Mendonça, M. A. S. Artes. In: Sabedoria: livro multidisciplinar $1^{\text {a }}$ série Ensino Médio. Londrina: Sapiens, 2015. p. 166-221.
} 
é de séculos. Já a Idade Contemporânea que compreende as últimas décadas é representada em uma escala ligeiramente maior.

Figura 2: Linha do tempo “Da pré-história à Idade Contemporânea”. Fonte: Mendonça, 2015 p.171

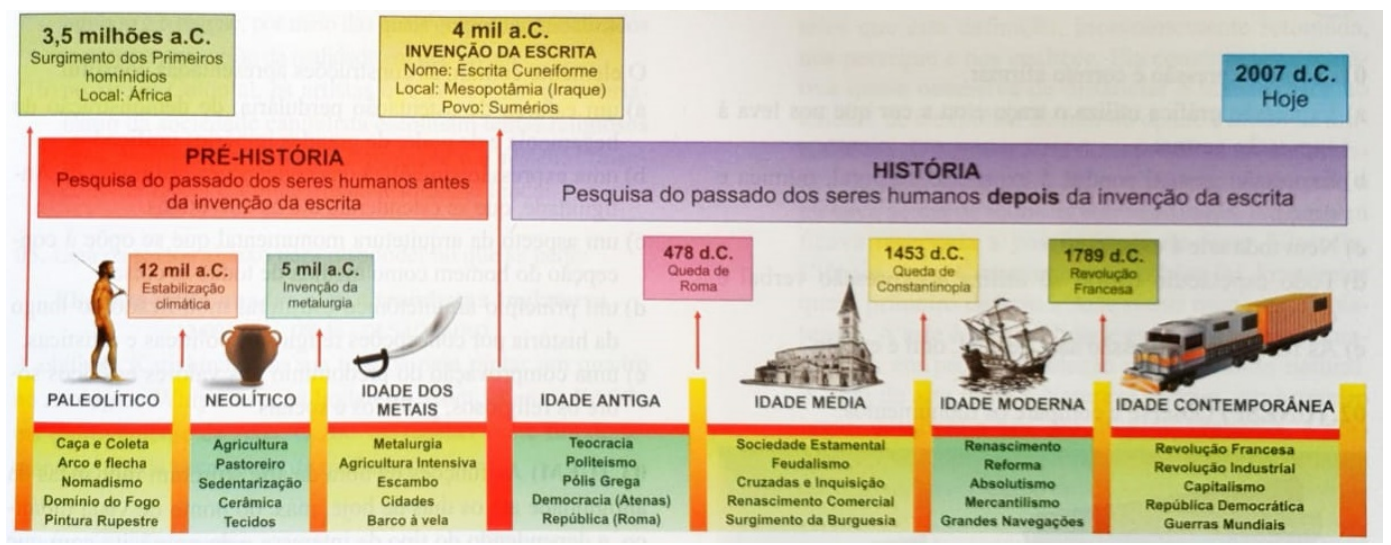

Já a figura 3 é uma das timelines do livro A História da Arte, de Ernst Gombrich (2015), na qual o autor faz um recorte temporal de 3000 a.C. a 2000 d.C. e adiciona uma nova camada de informação, a localização onde estes eventos ocorreram. Os espaços temporais, divididos em séculos e milênios, são representados respeitando-se uma escala. A simbolização, neste caso, é verbal/numérica e esquemática. Os períodos e movimentos artísticos são representados por linhas e os acontecimentos ou marcos históricos por pontos.

Este é um artefato bem construído que expõe os dados de forma clara, mas a ausência de imagens e as informações resumidas a palavras-chave exigem do leitor familiaridade com o tema ou interação com o texto para que seja compreendido.

Figura 3: Linha do Tempo Fonte: Gombrich, 2015, p.656

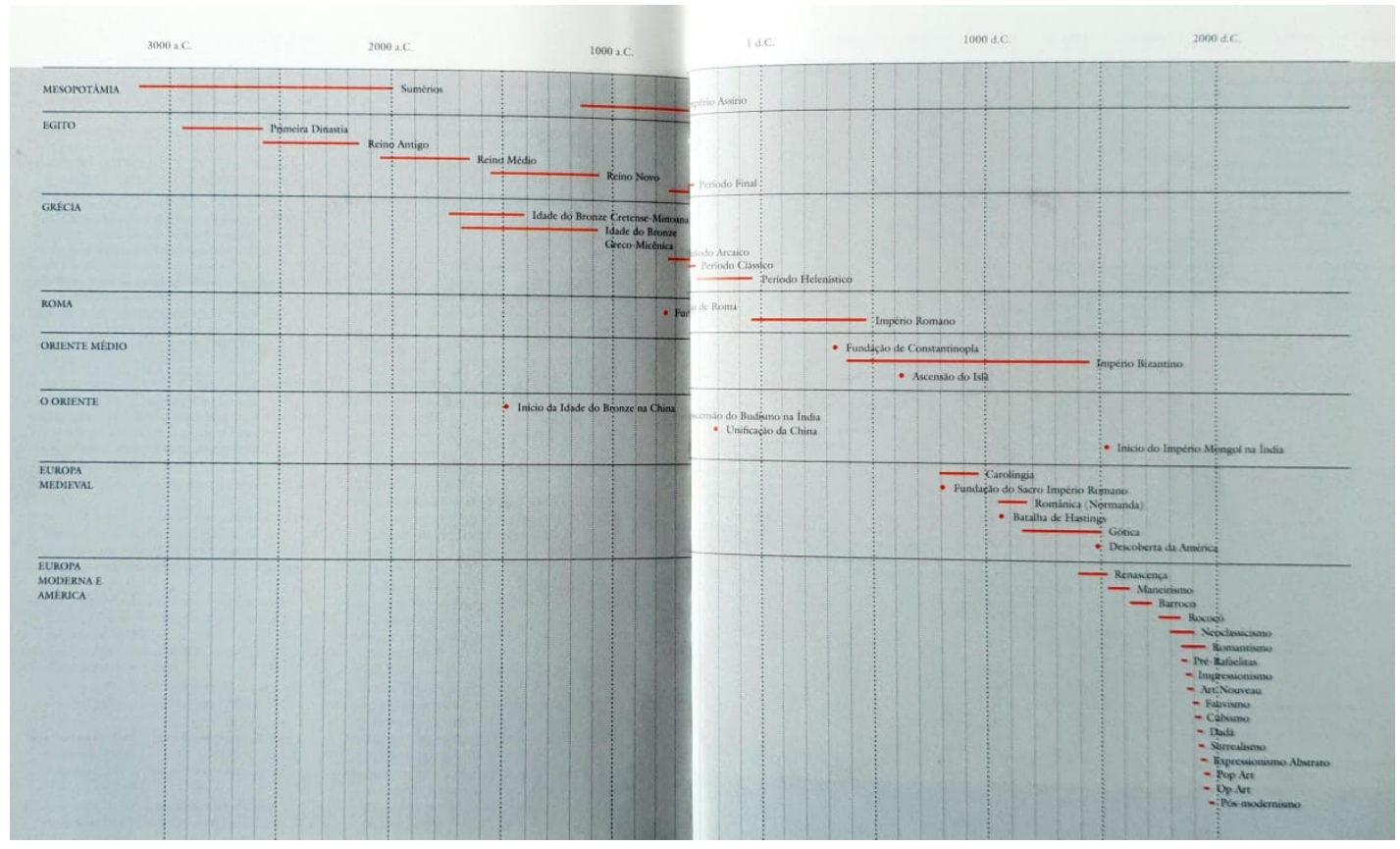




\section{Por que ir além da Timeline?}

Embora as linhas do tempo sejam muito importantes para apresentar dados historiográficos, geralmente tragam informações de "o que"? e "quando"? e possam ainda receber camadas de informação para responder a "quem" ou ainda "onde"? elas não se mostram tão eficazes em responder às questões "como"? e "por quê"? Por trazerem muitas informações num espaço visual reduzido, exigem o aprofundamento do leitor. Por isso decidiu-se investigar artefatos gráficos de outra natureza, que trouxessem diferentes recortes e mais camadas de informação sobre o tema determinado.

Para esta análise realizou-se uma pesquisa exploratória na plataforma Pinterest, rede social de compartilhamento de imagens, a partir de busca pelas palavras-chave Art e Infographics. A busca foi realizada primeiramente em português mas não trouxe resultados satisfatórios ${ }^{2}$. Foram selecionados três exemplos ${ }^{3}$ que abordam: a leitura de uma obra de arte, a produção de um artista e as características de um estilo ou movimento artístico.

\section{Análise do Infográfico "Las Meninas"}

A obra "As meninas" (figura 4) foi pintada por Diego Velazquez em 1656, e é um dos expoentes do Barroco Espanhol, cujas características são o grande contraste entre luz e sombra, a expressividade, a narrativa nas cenas e as composições mais complexas, muitas vezes compostas por várias personagens (Gombrich, 2015). Este é um quadro de grandes dimensões, em que o artista se retrata pintando uma tela igualmente colossal. Trata-se, portanto, de metalinguagem. Mas as personagens que ele retrata nesta tela não estão na cena, podem ser vistas apenas refletidas em um espelho ao fundo. Outras personagens aparecem na penumbra e, em primeiro plano, vemos três meninas, no centro da composição, que são "iluminadas" por uma claridade que parece entrar por uma janela lateral.

\footnotetext{
${ }^{2}$ É importante salientar que as redes sociais utilizam algoritmos relacionados aos interesses identificados pelo usuário tanto na criação da conta quanto no uso da plataforma, e que, portanto, os resultados podem variar bastante dependendo de quem faça a busca.

${ }^{3}$ Palavras-chave em inglês trouxeram artefatos na língua espanhola, o que pode ser resultado tanto de uma produção mais extensiva nesta língua quanto de algoritmos de localização do usuário na América Latina.
} 
Figura 4: Las Meninas, 1656. Fonte: https://www.museodelprado.es

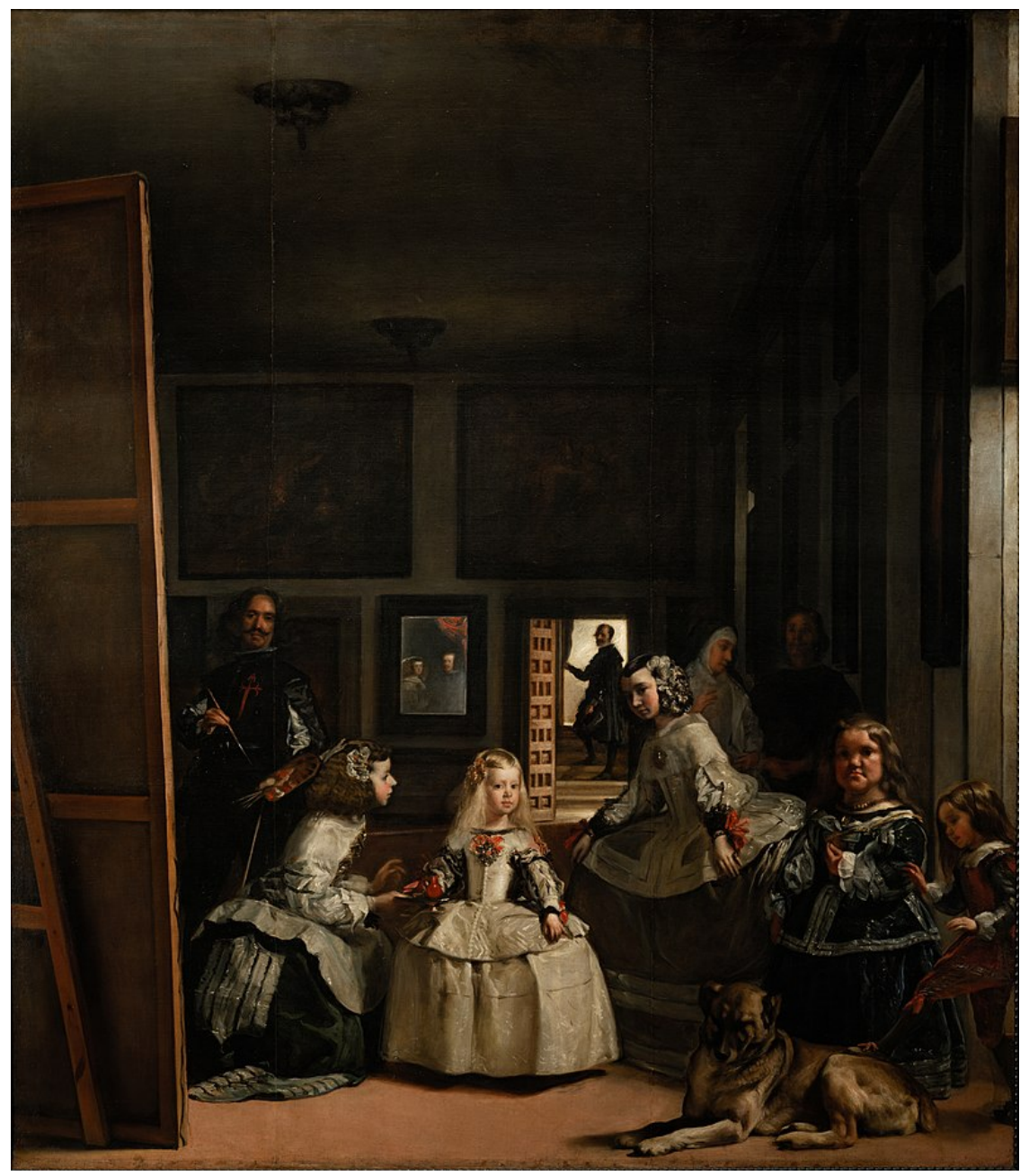

Quem são estas personagens e por que há tantas pessoas na sala? Quem é o homem que sai por uma porta ao fundo? São perguntas que a obra não responde, mas que o infográfico criado por Nestor Alonso (figura 5) ajuda a compreender. 
Figura 5: Infográfico “Las Meninas”. Fonte: http://arrukero.com/ple/ (autorizado pelo autor)

\section{Las Meninas}

Es uno de los cuadros más famosos de la historia del arte. Está en el Museo del Prado, en Madrid.
Es un retrato de grupo. Representa a la familia del rey Felipe IV.

Velázquez er a el pintor de la Corte.

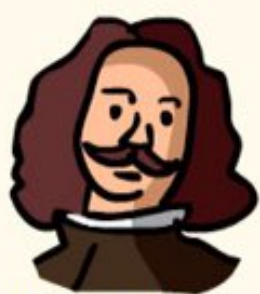

Diego Velazquez lo pinto en 1656.

\section{El pintor también En realidad Velazquez se autorretrata esta pintando a los en el cuadro. \\ reyes, que se reflejan en \\ El aposentador de palacio. Don Jose Nieto. Era una especie de mayordomo.}

1 este espejo.

Don Diego de Azcona y Doña Marcela de Ulloa, dos religiosos y educadores de la
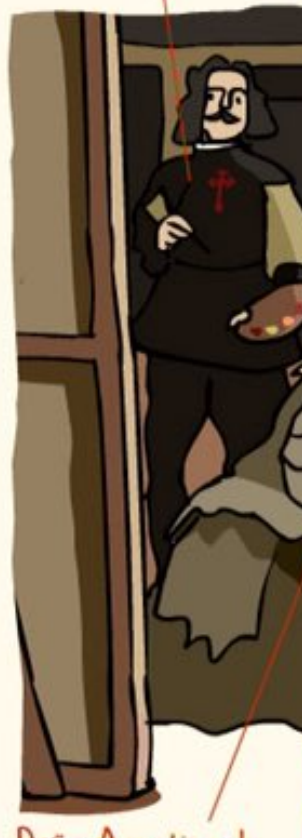

Doña Agustina de Sarmiento, una de las dos damas de compañia. 1 infanta.

\section{La escena recoge el momento en que la} infanta Margarita entra en el estudio donde el pintor esta retratando a los reyes, que estan sentados enfrente. Velázquez utiliza un recurso conocido como "el cuadro dentro del cuadro", y que también usaron otros artistas de su epoca.

Dona lsabel de Velasco, dama hija de los rejes. y figura central de la escena. de la nobleza al igual que Doña Agustina. 1 8 की 5.5) MariBarbola y Nicolás
Pertusato, dos enanos de compañia. $\int_{0}, 2$ E (2)

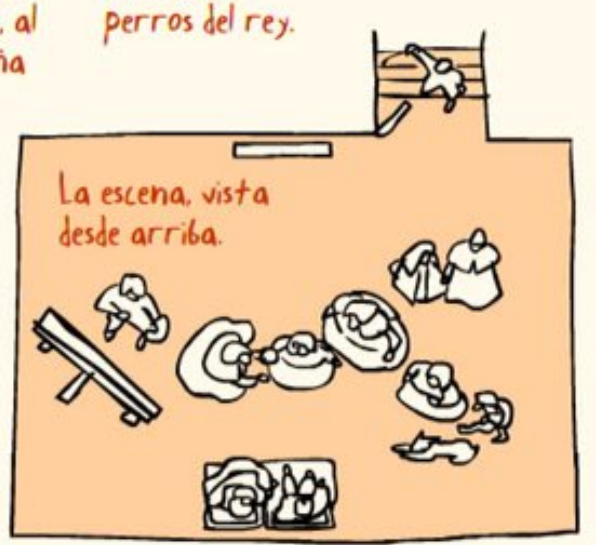

Nestor Alonso 
De natureza exploratória e explanatória (responde às questões "o que"?, "quem"? "onde"? "como" e "por quê"?), o infográfico traz uma representação conotativa da cena, com linhas simples e preenchimento em cores chapadas que remete à ilustração de histórias em quadrinhos. Esta representação torna mais clara a quantidade de pessoas em cena, algo difícil de identificar pela falta de iluminação na obra original.

Na parte superior, junto ao título, o autor apresenta em poucas palavras, as informações principais sobre a obra e o artista. As informações sobre cada personagem são dispostas em textos curtos em torno da imagem e direcionadas por uma linha como em um sketch (utiliza simbolização pictórica e verbal com configuração não linear mas com visualização direcionada).

O autorretrato do artista é evidenciado pela figura (do lado direito, acima), que traz informações sobre o autor e a data de realização da obra, cuja fisionomia é semelhante à da personagem retratada pintando uma grande tela, da qual vemos apenas uma parte do verso.

Há ainda a adição de uma nova camada de informação textual na parte inferior, que contextualiza a cena retratada e uma "planta baixa" do ambiente posicionando cada uma das personagens. Este posicionamento facilita compreender que o casal real, que posa para o retrato e que aparece no quadro refletido em um espelho ao fundo, estaria à frente da cena, na mesma posição do espectador. Também localiza os planos em que estão as personagens que aparecem agrupadas do lado direito, além de indicar a distância a que se encontra o homem ao fundo, que parece sair por uma porta e subir pela escada. O autor deste infográfico é espanhol, professor de escola pública e mantém uma página onde divulga infográficos sobre temas diversos, o que explica o caráter didático percebido neste artefato.

\subsection{Análise do Infográfico " 25 años sin Salvador Dali"”}

Para a análise da trajetória de um artista foi selecionado o infográfico "25 años sin Salvador Dali" (figura 6) produzido por Elizabeth Garcia Alvarado para uma agência de notícias mexicana pela passagem dos 25 anos de morte do artista. É historiográfico pois traz uma linha do tempo da vida de Dalí mas também apresenta informações sobre suas obras, as diferentes técnicas desenvolvidas pelo artista ao longo de sua trajetória e sua relação com o surrealismo.

A simbolização da timeline é verbal e numérica mas não é linear, representada do lado esquerdo, em formato de semi-círculo. A forma circular se repete na apresentação das principais obras à direita, possivelmente associada à obra "Galatea em esferas" (figura 7) na qual o artista retrata sua musa com uma composição de esferas. Pode-se dizer que a infografista utilizou o recurso da redundância, que reforça a mensagem ao utilizar a mesma forma da obra para nortear a composição do artefato.

A configuração do infográfico neste caso é linear-interrompida e a leitura se dá da esquerda para a direita, tanto para o texto quanto para as imagens, sequência similar à das histórias em quadrinhos.

No centro da linha do tempo há uma fotografia do artista, com os olhos expressivos e os bigodes arqueados, imagem popularizada em um seriado espanhol. A representação, no entanto, é não naturalista ou conotativa, uma vez que a autora utiliza a operação retórica da supressão ao 
retirar parte da cabeça do artista de onde vemos "surgir" elementos de suas obras, uma metáfora onde o cérebro é substituído por suas criações. Percebe-se que para falar de um dos principais artistas do surrealismo a autora utiliza-se de uma representação surrealista, redundância que auxilia na compreensão de características do movimento através do artefato.

Figura 6: Infográfico "25 años sin Salvador Dali”. Fonte: http://www.poblanerias.com/2014/01/25-anos-sinsalvador-dali/ (autorizado pela autora)

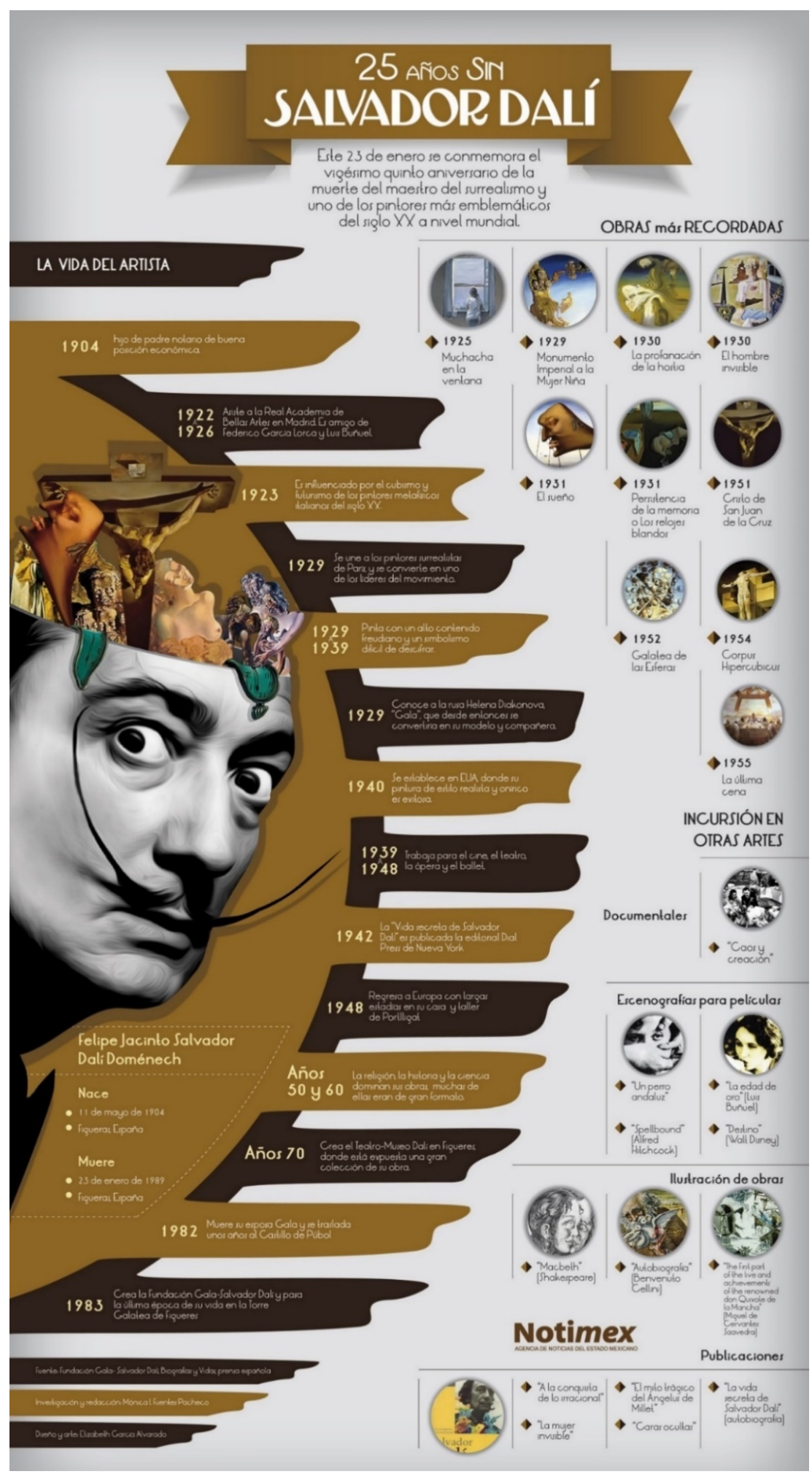


Figura 7: Galatea em esferas Fonte: https://www.salvador-dali.org

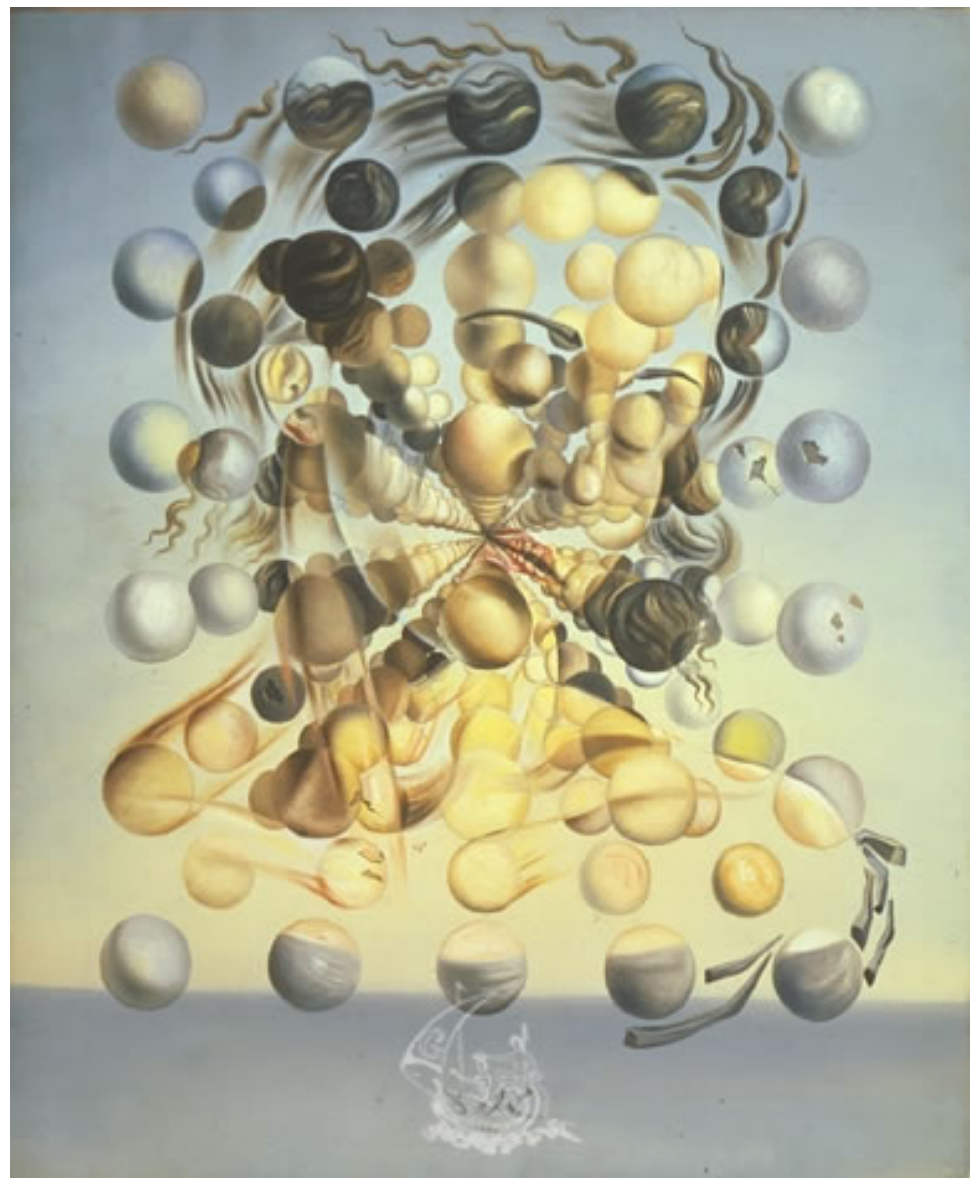

\section{Análise do Infográfico “¿Art Nouveau? Alphonse Mucha te lo explica”}

O Infográfico "¿Art Nouveau? Alphonse Mucha te lo explica” (figura 8) foi selecionado para exemplificar as características de um movimento ou estilo, neste caso a Arte Nouveau. Postado por Javi Torres na página Cultura Colectiva, cita como fonte das informações a Enciclopédia Britânica. É Exploratório e Explanatório pois responde às questões "O que"? "Quem"? "Onde"? "Como"? e "Por quê"?

A simbolização é Pictórica e Verbal/Numérica e a configuração não linear tem visualização direcionada da esquerda para a direita em blocos curtos de informação verbal, o que remete às histórias em quadrinhos. Há utilização de metáfora e substituição dos elementos esquemáticos por partes do corpo (cabelos, mãos), plantas e fumaça. Caracteriza-se aqui a redundância, recurso que ajuda na memorização, uma vez que utiliza os elementos da natureza como ornamentos para "emoldurar" o texto que justamente descreve ser esta uma característica deste estilo. A utilização de cores em tons pastéis, sem grandes contrastes ou profundidade, também são características do movimento que se repetem no infográfico.

A tipografia, apesar do excesso de ornamentação característica do estilo, tem boa legibilidade e remete às dos cartazes de Alphonse Mucha, artista citado no título e que no canto inferior direito aparece entre os "grandes expoentes" do movimento. 
Figura 8: Infográfico “¿Art Nouveau? Alphonse Mucha te lo explica” Fonte:

https://culturacolectiva.com/infografias-cc/art-nouveau-el-final-de-las-viejas-esteticas

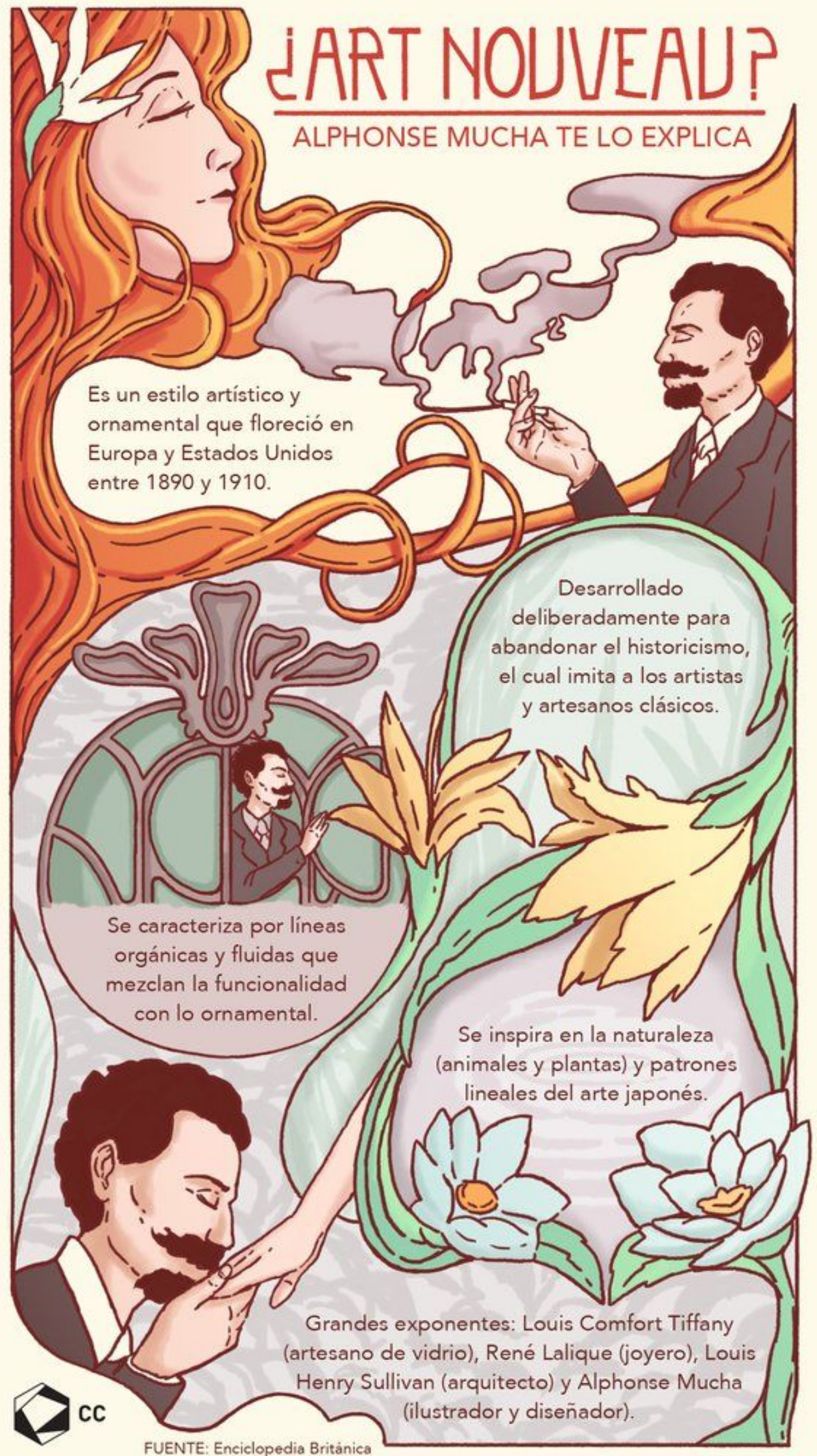




\section{Discussão dos resultados}

Os infográficos analisados têm naturezas diversas, trazem mais camadas de informação (contextualização) de maneira clara e concisa, para melhorar a compreensão. Nos três casos o tamanho da fonte é pequeno para visualização em telas de computador ou smartphone, mas o recurso de zoom presente nestes dispositivos soluciona o problema.

A representação com linhas simples e linguagem conotativa, que remete a histórias em quadrinhos, pode "quebrar a barreira" em relação à arte, por ser uma linguagem já conhecida dos jovens, além da utilização de recursos como metáfora e redundância que favorecem compreensão e memorização.

Segundo Mello (2016), o acesso ao conteúdo nestes artefatos deve ser rápido, porém com o cuidado de não sacrificar a complexidade dos dados. O uso apropriado dos elementos na composição é essencial para guiar o leitor, dar significado, revelar relações e levar a conclusões. Estes requisitos foram observados nos exemplos analisados.

\section{Considerações Finais}

Foram identificadas nas teorias de aprendizagem congruências em relação à combinação de texto e imagem para despertar o interesse e melhorar a aprendizagem dos estudantes. Também se observou que relacionar novos conteúdos com conhecimentos prévios pode facilitar a compreensão e memorização, tornando a aprendizagem significativa, além de diminuir o esforço cognitivo. $\mathrm{O}$ acesso às redes sociais pode ter se intensificado na pandemia de Covid-19, tornando o ambiente virtual cada vez mais a "realidade" do estudante, o que justifica utilizar este meio como fonte de recursos para uso didático.

A análise dos Infográficos revelou que os recursos visuais utilizados em sua elaboração facilitam a visualização de várias informações simultaneamente e contribuem para a contextualização ao trazerem dados adicionais. Conotação e redundância, observadas nos três exemplos, podem colaborar para a compreensão de conceitos e memorização. Avaliou-se também que a linguagem utilizada nestes artefatos é descomplicada e lúdica, remete à histórias em quadrinhos, e pode atrair a atenção e interesse dos alunos o que torna este material potencial introdutório para uso em contexto escolar.

A orientação e mediação do professor são importantes para alertar o aluno quanto à confiabilidade dos dados extraídos da internet, a necessidade de buscar aprofundamento na literatura e desenvolver criticidade em relação aos conteúdos disponíveis em redes sociais.

Esta pesquisa mostra a potencialidade dos infográficos como recurso didático, não apenas em Arte mas também nas demais disciplinas, e sugere-se como atividade de aprendizagem a leitura crítica destes artefatos e das timelines.

É importante observar que a análise foi realizada pela perspectiva do professor e há necessidade de validação dos resultados em sala de aula. 


\section{Referências}

Barbosa, A. M. (2005) Dilemas da Arte/Educação como mediação cultural em namoro com as tecnologias contemporâneas. In: Ana Mae Barbosa (org.). Arte/Educação contemporânea: consonâncias Internacionais. Org.. São Paulo: Cortez, p. 98- 112.

Brasil. (2018) Ministério da Educação. Base Nacional Comum Curricular. Brasília, 2018.

Cánovas, Cristóbal Pagán; Coulson, Seana; Jensen, Max. (2011) Timelines: Conceptual integration, emotion, and poetic effects. Project Creatime: Time in the creative mind. Disponível em https://www.researchgate.net/publication/287065510_Timelines_Conceptual_integration_em otion_and_poetic_effect. Acesso em 26 abr 2021.

Cardoso, Rafael. (2008) Uma Introdução à História do Design. São Paulo: Blucher, 3. Ed.

Cook, Michelle Patrick. (2006) Visual Representations in Science Education: The Influence of Prior Knowledge and Cognitive Load Theory on Instructional Design Principles

Coutinho, S. G. (2006) Design da Informação para Educação. InfoDesign Revista Brasileira de Design da Informação, V. 3 - n. 1/2, p. 49-60.

Duarte, Fernando. (2019) Brasil é 'vice' em tempo gasto em redes em ranking dominado por 'emergentes' BBC News Brasil, São Paulo 6 set. 2019. Disponível em https://www.bbc.com/portuguese/geral-49602237. Acesso em 20 de abr. 2021

Escobar, Bolivar Teston De; Spinillo, Carla Galvão. (2016) Retórica visual na infografia sobre saúde. InfoDesign, v. 16. n. 2. p. 162-179.

Frederico, Fernando Temporini; Gianotto, Dulcinéia Ester Pagani. (2018) Contribuição das imagens para o ensino de física numa perspectiva da Teoria da Dupla Codificação. Revista Electrónica de Enseñanza de las Ciencias Vol. 17, No 1, 200-222

Freire, Paulo. (2002) Pedagogia da Autonomia: saberes necessários à prática educativa. $25^{\mathrm{a}}$ ed. São Paulo: Editora Paz e Terra.

Gombrich, Ernst Hans. (2015) A História da Arte. 16.ed. Rio de Janeiro: LTC.

Lonsdale, Maria; Lonsdale, David. (2019) Design 2 Inform. The Office of the Chief Scientific Advisor | Gov UK. Londres.

Maass, M. C. (2011) Design e Cidadania: defesa da Educação Artística. Tese de Doutorado. Universidade de Brasília, Departamento de Arquitetura e Urbanismo.

Mello, Adriane C. K. A. (2016) Entre o objeto e o processo: o infográfico nas artes visuais. $25^{\circ}$ Encontro da ANPAP. Porto Alegre. p. 93-105. Disponível em http://anpap.org.br/anais/2016/comites/ceav/adriane_mello.pdf

Moreira, M. A. (2012) ¿Al afinal, qué es aprendizaje siginificativo? Qurriculum : revista de teoría, investigación y práctica educativa. La Laguna, Espanha. No. 25 (marzo 2012), p. $29-56$

Mozota, Bridge B. (2003) Design Management: Using Design to Build Value and Corporation Innovation. New York: Allworth Press.

Naparin, Husni; Saad, Aslina Binti. (2017) Infographics in education: review on infographics design. In: The International Journal of Multimedia \& Its Applications (IJMA) Vol.9, No.4/5/6, December. 
Oliveira, Í. S. C. S.; Souza, A. P. C; Coutinho, S. G.; Miranda, E. R. (2017) Explorando conceitos - pesquisa bibliográfica e elaboração de infográfico sobre definições do campo de Design da Informação. Revista brasileira de Design da Informação- Infodesign, v. 16 n. 3 p. 285-308 São Paulo

Rajamanickam, V. (2005) Infographics Seminar Handout. Seminars on Infographic Design, National Institute of Design, Ahmedabad, and the Industrial Design Centre, Indian Institute of Technology, Bombay. Disponível em:

<http://www..schrockguide.net/uploads/3/9/2/2/392267/infographic_handout.pdf> Acesso em 12 mai 2021

Ribas, Beatriz. (2004) Infografia Multimídia: Um modelo narrativo para o webjornalismo. Anais do $V$ Congreso Iberoamericano de Periodismo en Internet, FACOM/UFBA,

Rudolph, Michelle. (2017) Cognitive Theory of Multimedia Learning. Journal of Online Higher Education vol. 1, no. 2.

Siricharoen, W. V. (2013) Infographics the new communication tools in digital age. The International Conference on E-Technologies and Business on the Web (EBW2013) UTTC Bangkok, Thailand, 2013 169-174 -

Sociedade Brasileira De Design Da Informação (SBDI). (2020) Disponível em: <http://www.sbdi.org.br/definicoes>. Acesso em: 26 abr 2021.

Twyman, Michael. (1979) A Schema for the Study of Graphic Language (Tutorial Paper). In: Kolers, P. A.; Wrolstad, M. E.; Bouma, H. (editores). Processing of Visible Language. NATO Conference Series, v. 13. Boston: Springer, p. 117-150.

Yu, Chien; Brandenburg, Teri.(2011) Multimedia database applications: issues and concerns for classroom teaching. The International Journal of Multimedia \& Its Applications (IJMA) Vol.3, No.1

\section{Sobre as autoras}

Marcele Cristiane Minozzo. Me., UFPR, Brasil <minozzo.marcele@gmail.com>

Carolina Calomeno Machado, Dra., UFPR, Brasil < carolcalomeno.ufpr@gmail.com> 